\title{
An unusual case of a very large Ameloblastic fibroma
}

\author{
Bhatnagar $\mathbf{S}^{1}$, Gangwani $\mathrm{A}^{2}$, Khare $\mathbf{P}^{3}$ \\ ${ }^{1}$ Dr Shweta Bhatnagar, Assistant Professor, Department of Dentistry, ${ }^{2}$ Dr Amar Gangwani, Assistant Professor, Department \\ of Pathology, ${ }^{3}$ Dr Praveen Khare Assistant Professor. All affiliated with Bundelkhand Medical College Sagar, Madhya \\ Pradesh, India
}

Address for correspondance: Dr. Shweta Bhatnagar, Email: shwetakeshav@gmail.com

\begin{abstract}
Ameloblastic fibroma is usually seen in children and teenagers. It is a rare mixed odontogenic tumor; it is found predominantly in children and therefore is an important diagnostic consideration. A female patient of age 13 years reported to the hospital with complaint of mass in her mouth since two years. The microscopic examination revealed strands and buds of ameloblastic epithelium embedded in cellular neoplastic fibrous stroma suggesting of ameloblastic fibroma. The case of ameloblastic fibroma is being reported for its unusual presentation which involved two third of mandible. The high recurrence rate of the tumor emphasizes the need of early diagnosis; adequate excision and a long term follow up.
\end{abstract}

Key words: Ameloblastic fibroma, Odontogenic tumor

\section{Introduction}

Ameloblastic fibroma is a rare mixed odontogenic tumor; it is found predominantly in children and therefore is an important diagnostic consideration. ${ }^{1}$ It can appear in either maxilla or mandible, most common site being posterior mandible. Impacted teeth are usually associated with the swelling. ${ }^{2}$ Radiographic appearance may vary from a small unilocular lesion to an extensive multilocular lesion. Bone expansion and tooth dislocation are common. ${ }^{3}$ Primary lesions can be treated with enucleation or curettage and the tumor has a low rate of recurrence. ${ }^{4}$ However, in a large and extensive lesion radical surgical approach might be required..$^{5}$

\section{Case Report}

A female patient of age 13 years reported to the hospital with a complaint of mass in her mouth since two years.

Initially it was a small mass which gradually increased to the present size. On inspection the tumor extended from preauricular region to the chin and from the lower border of mandible to around one $\mathrm{cm}$ above the commisure of lip (Fig 1). On palpation, it was semisolid, nontender tumor which extended from left mandible condylar region to the right body of mandible. The buccal and lingual plates were felt expanded. A CT- scan with 3D reconstruction

Manuscript received: $24^{\text {th }}$ Dec 2013

Reviewed: $29^{\text {th }}$ Dec 2013

Author Corrected: $25^{\text {th }}$ Jan 2014

Accepted for Publication: 29th Jan 2014 was advised which confirmed mandibular tumor with multiple impacted teeth (Fig 6). The fine needle aspiration was negative for malignant cells. A provisional diagnosis of odontogenic tumor was made. An incisional biopsy was planned. Macroscopically, a rubbery white soft tissue was observed.

The microscopic examination revealed strands and buds of ameloblastic epithelium embedded in cellular neoplastic fibrous stroma, representing a primitive dental papilla suggesting of Ameloblastic fibroma (Fig $3 \& 4$ ). Based on clinical history, age of the patient, radiographic imaging and microscopic data, diagnosis of Ameloblastic Fibroma was established. Owing to the extent of lesion mandibulectomy was planned with immediate reconstruction. The supraperiosteal flap was reflected on the affected side. The bone was exposed in the 36 region and osteotomy was performed.

The mandible was released of its labial and lingual attachment and the whole tumor was delivered in toto. Immediate reconstruction by rigid fixation $2.4 \mathrm{~mm}$ titanium plate was done. Grossly the tumor involved two third of mandible around $18 \mathrm{~cm}$ in length and $7 \mathrm{~cm}$ in width, was sent for histopathology which confirmed it to be benign ameloblastic fibroma.

The patient is asymptomatic one year postoperatively (Fig 2 ). The outcome was esthetically satisfactory and there have been no signs of recurrence. 


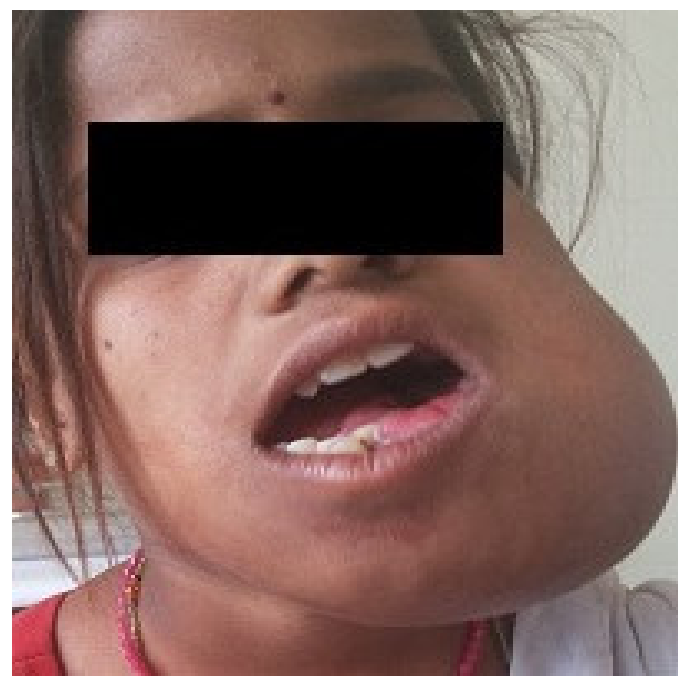

Fig 1: Gross appearance of Madibular Swelling

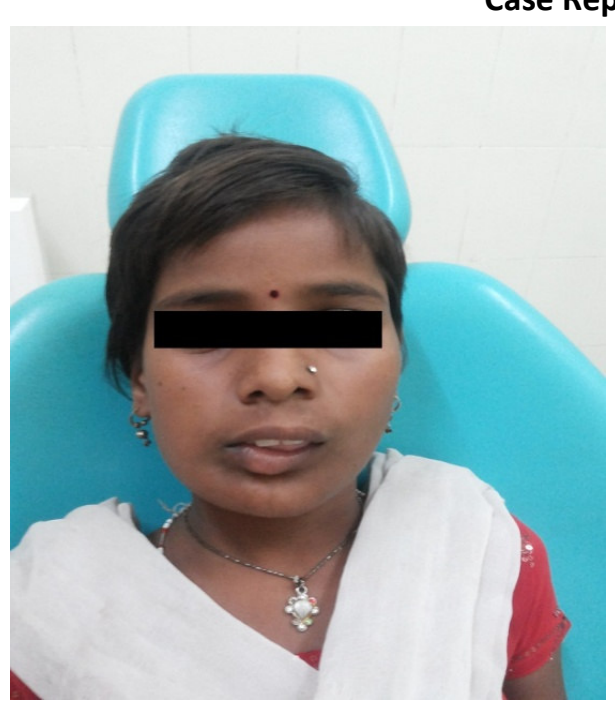

Fig 2: Post operative after resection of tumor

\section{Discussion}

Ameloblastic fibroma is usually seen in children and teenagers. The mean age range is 6-12 years. ${ }^{6,7}$ Age of patient is slightly above mean age of presentation being 13 years. The posterior mandible is preferred site. In our patient the ameloblastic fibroma involved an unusually large area around $16 \mathrm{~cm}$.

The radiographic appearance may vary from a small unilocular lesion to an extensive multilocular lesion. ${ }^{8}$ In the case reported, radiographic examination revealed multilocular appearance with multiple impacted and displaced teeth.

Histologically, AF is tumors that do not show inductive changes and calcified changes. They consist of active mesenchymal and epithelial components. It resembles dental papilla. ${ }^{6}$ Ameloblastic fibrodontoma (AFO) is defined as a tumor that shares many features with AF but has enamel and dentin in its interior. ${ }^{9}$ Chen et al considered this lesion as an intermediate stage in development of an odontoma, with the primary stage of formation being AF. ${ }^{10}$

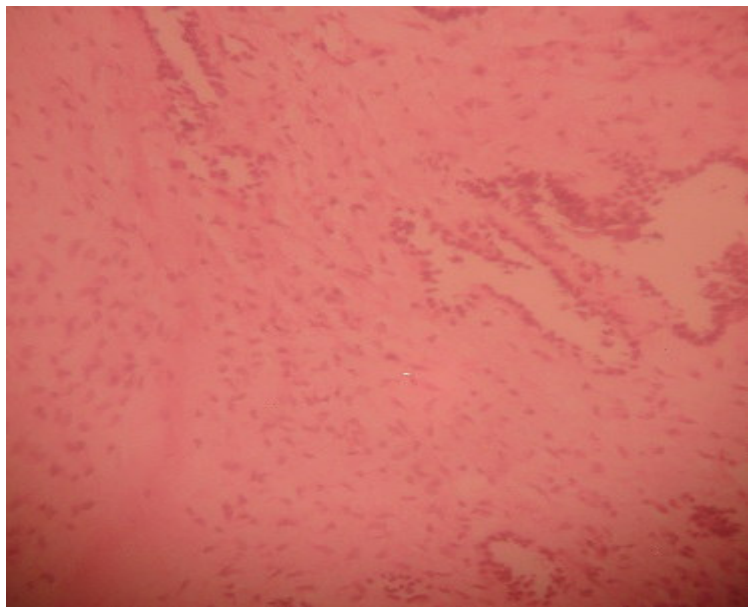

Fig 3: Histopathology slide H\&E 10x

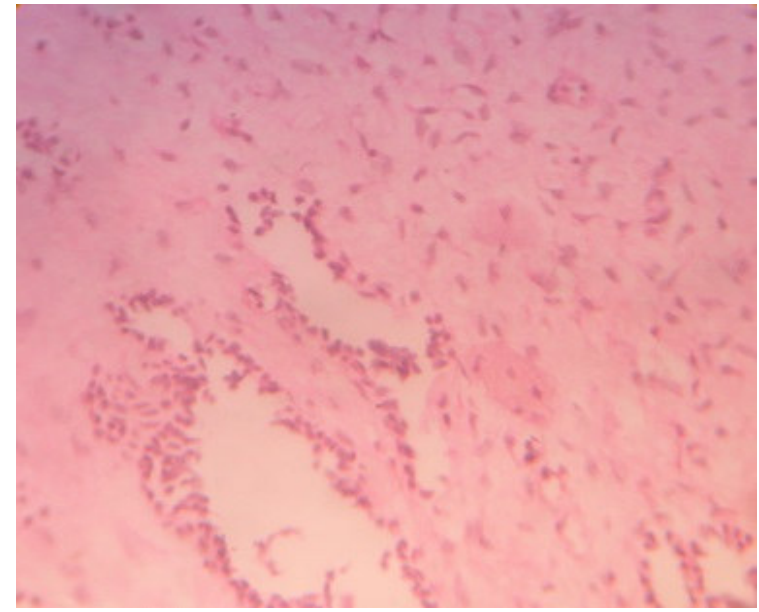

Fig 4: Histopathology slide H \& E 40x showing ameloblastic epithelium embedded in fibrous stroma

There is difference of opinion regarding treatment due to different recurrence rates described in literature. The recurrence rate of $43.5 \%$ was reported by Trodahl ${ }^{2}$.

According to Zallen et $\mathrm{al}^{11}$ block resection was recommended as a initial treatment modality due to high recurrence rate in cases in which conservative approach was initially performed. 
Dallera et $\mathrm{al}^{12}$ presented a long term follow up of six cases in which conservative approach was performed and good results were achieved. However, prognosis for lesion of the proportion as seen in our case is dubious by only conservative management. Hence, resection with immediate reconstruction was done.
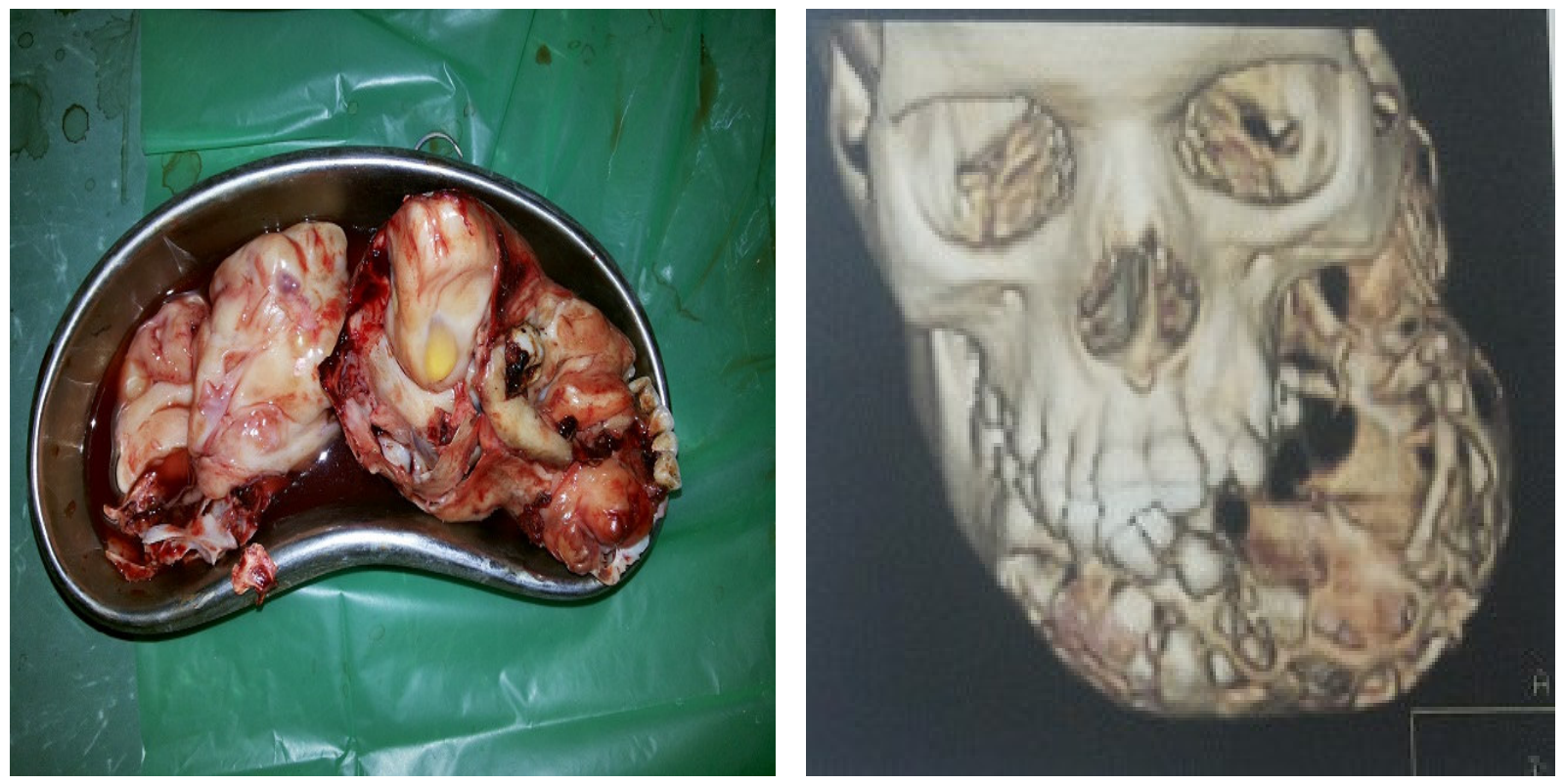

Fig 5: Gross Excised Specimen

\section{Conclusion}

Ameloblastic fibroma should be considered as a differential diagnosis for large masses of mandible in pediatric age group.

The patient should be kept under long term follow-up as suggested for all lesions of AF.

Funding: Nil

Conflict of interest: Nil

Permission from IRB: Yes

\section{References}

1. Mahapatra PK, Choudhry MR, Parkash H. Ameloblastic fibroma in the midline of mandible. A case Report J clinical and pediatric Dentistry 2000; 24(4): 321327

2. Trodahl JN. Ameloblastic fibroma. A survey of cases from the Armed Forces Institute of Pathology. Oral surgery oral medicine oral pathology 1972; 33(4): 547548

3. Neville BW, Damm DD, Allen CM, Bouquot JR. Oral and Maxillofacial Pathology. Saunders Philadelphia; 1995:493-540
Fig 6: 3D CT-Scan showing extent of lesion with multiple impacted teeth

4. Chindia ML, Akama MK, Awange DO. Ameloblastic fibroma at the University of Nairobi Dental Hospital. East Afr Med J. 2005; 82(8):418-421.

5. Vasconcelos Belmiro CE, Andrade Emanuel SS, Rocha Nelson S, Morais Hecio HA, Carvalho Ricardo W F. Treatment of large ameloblastic fibroma : a case report. J of oral science 2009; 51(2):293-296

6. Marx RE, Stern D. Oral and maxillofacial pathology. quintessence, illinos,2003;675-678

7. Jones AV, Franklin CD. An analysis of oral and maxillofacial pathology found in children over a 30 year period. Int j paediatric dentistry2006; 16(1):19-30.

8. Bozic M, Hren NI. Ameloblastic fibroma. J radiol oncol 2006;40(1):35-38

9. Martin - Granizo Lopez R, Ortega L, Gonzalez corchon M A, Berguer Sandez A. Ameloblastic fibroma of the mandible. Report of two cases. Med oral 2003;8(2), 150153

10. Chen Y, Wang JM, Li TJ Ameloblastic Fibroma: a review of published studies with special reference to its nature and biological behaviour. Oral oncol 2007; 43(10), 960-969. 
11. Zallen RD, Preskar MH, Mc Clary SA. Ameloblastic fibroma. J Oral Maxillofacial Surgery. 1982;40(8): 513-517
12. Dalera P, Bertoni F, Marchetti C, Bacchini P, Campobassi A.Ameloblastic fibroma:Afollow-up of six cases. Int J Oral Maxillofacial Surgery.1996;25(3): 199-202

How to cite this article?

Bhatnagar S, Gangwani A, Khare P. An unusual case of a very large Ameloblastic fibroma. Int J Med Res Rev 2014;2(1): 70-73, 10.17511/ijmrr.2014.i01.13 